\title{
Application of Inventory Model in Determining Stock Control in an Organization
}

\author{
Hycinth Chukwudi Iwu ${ }^{1}$, Chukwudi J. Ogbonna ${ }^{1}$, Opara Jude ${ }^{2, *}$, Kalu Georgina Onuma ${ }^{1}$ \\ ${ }^{1}$ Federal University of Technology Owerri Nigeria PMB 1526, Owerri Nigeria \\ ${ }^{2}$ Department of Statistics, Imo State University PMB 2000, Owerri Nigeria \\ *Corresponding author: judend88@yahoo.com
}

Received January 08, 2014; Revised April 12, 2014; Accepted September 21, 2014

\begin{abstract}
This paper investigates the application of inventory model in determining stock control in an organization. A multi-product Economic Order Quantity model was used to determine the optimal order times. The result of the analysis revealed that J.O. Adimoha's investment does not have a proper inventory management which leads them to sometimes either over stock or under stock. The combination of orders at different time interval was carefully and constantly updated and verified because reorder points and EOQ may change. In conclusion, it was discovered that reorder points often coincides close together.
\end{abstract}

Keywords: inventory, economic order quantity, average stock, abc analysis, holding cost, safety stock

Cite This Article: Hycinth Chukwudi Iwu, Chukwudi J. Ogbonna, Opara Jude, and Kalu Georgina Onuma, "Application of Inventory Model in Determining Stock Control in an Organization." American Journal of Applied Mathematics and Statistics, vol. 2, no. 5 (2014): 307-317. doi: 10.12691/ajams-2-5-3.

\section{Introduction}

Inventory or stock control is a quantitative control technique with strong financial implications. For many organizations, inventory control is the single most important control technique having direct relationships with production, purchasing, marketing and financial policies [1].

Inventory management or stock management or inventory control or tock control has the same meaning.

Stock control means inventories held on a controlled basis. Stocks are held for two reasons which are: (a) economy and (b) for protection. It is held for economy in the sense that we want to purchase and maintain that quantity which minimizes total annual inventory cost. It is held for protection in the sense that we do not want to experience stock-out. Protection also means providing a buffer against fluctuations in demand or delivery, insuring against uncertainty and delay [2].

Business organizations carry stock because it pays them to do so. In a manufacturing company, three types of inventory are held, they are raw materials inventory, work-in-progress inventory and finished goods inventory.

An inventory problem occurs when there is need to stock goods or Commodities in order to satisfy demand over a specified period of time. Almost every business must stock goods to ensure smooth and efficient handlings of its operations. The demand to stock goods may be satisfied by stocking once for the period of time concerned or by stocking gradually for every time during the time horizon.

An inventory problem is characterized by decision regarding how much goods a firm could order and when to order such goods. Both over stocking and under stocking of goods could create problems for any firm.

An understanding would increase the invested capital per unit time as well as the risk of running out of stock thus incurring customers service cost like cost of shortages, loss of goodwill, loss of trade and the like.

On the other hand, over-stocking of goods attracts unnecessary costs to the organization. Any item held in stock is capital tied up. (Holding costs comprise of shortages facilities, provision of services to such facilities, insurance on stocks, costs of loss, breakage, deterioration, obsolescence and the opportunity cost or loss of interest on the capital tied up).

Stock holding is necessary for any form of to decide how much and how often to order goods in order to minimize the cost involved. There is therefore the need to take decision based on the minimization of an appropriate cost function which will balance the total cost resulting from over-stocking and under-stocking.

\section{Statement of Problem}

Inadequate control of inventories can result in both under and over stocking of items. Under stocking results in missed deliveries, lost sales, dissatisfied customers. Overstocking unnecessarily ties up funds that might be more productive elsewhere. Even though overstocking may appear to be lesser of the two, the price tag for excessive overstocking can be staggering when inventory holding costs are high and matters can easily get out of hand.

The focus of this study is to help the supermarket maintain inventory levels at lowest cost possible while 
meeting customers demand. It will also help them to guard against out of stock syndrome through a proper inventory management .More so, it will help them in avoiding lower ordering costs as well as overstocking and the last but not the least is that it will help them in avoiding shortage of stocks.

As a result of all these, J.O Adimoha's investment has been encountering these problems of maintaining accurate and optimum stock level in its supermarket.

\section{Rationale for Study}

The job of many controllers (stock managers) is to maintain a given and reasonable stock level in order to optimize the total annual cost of maintaining such inventories. Demands are received and must be met by issuing out goods. The stock controller should then determine the quantity of items necessary to replenish the consumed stock so as not to experience shortage or manufacturing hold up. This control decision is a continuous one which is by no means easy unless efforts were made originally to design appropriate inventory policies upon which this decision may be based.

Inventory planning and control is a comprehensive exercise which comprises the policies, procedures, programs and strategies which an organization uses to regulate the range of items held in stock, and the amount of replenishment stock required for efficient operation. These borders on the following three questions each time

a. Which items should be held in stock?

b. What should be the required quantity of each?

c. When should a reorder be necessary?

These are three fundamental questions/problems in inventory planning decisions faced by J. O Adimoha's investment that needed to be solved.

Thus, the rationale of this study is to formulate an inventory control model that will assist the supermarket solve some of her inventory related problems as earlier discussed.

\section{Review of Related Literature}

Over the years, certain models have been developed to support the efforts made in production and retailing to cut down inventory-related cost. These models take into account the intricate peculiarities of production and retailing and show how inventory-related cost may be minimized when the rules of the models are adhered to. The unifying goals of the models, and indeed the goal of inventory control is to determine the optimal quantity of goals to order for and then to place an order given the contingencies and peculiarities of a particular business scenario.

In business.com, inventory model is defined as "a mathematical equation that enables organizations to determine the optimal quantity and the frequency of ordering and keeping goods and services available to the customer without interruption or delay”.

According to Business Dictionary.com inventory model is "a mathematical equation or formula that helps a firm in determining the economic order quantity, and the frequency of ordering, to keep goods, or services flowing to the customer without interruption or delay”.
According to Barrow's Accounting Dictionary, "inventory models are quantitative models designed to control inventory cost by determining the optimal time to place an order (or begin production) and the optimal order quantity (or production run). The timing of an order can be periodic (placing an order every $\mathrm{x}$ days) or perpetual (placing an order whenever the inventory declines to $\mathrm{x}$ units)".

It was determined from the data analysis that was done that an inventory models has to be developed for the smooth running in determining stock control in an organization. Literature studies were done on similar scenarios and different inventory model possibilities were identified.

This study was approached in as investigation of a multi-product production items and inventory model using the net present value [3]. During his study, combination of a fixed-order EOQ model and multi-product EOQ model was most probably sufficient. It was also found that reorder points and EOQ may change and also in EOQ models, the reorder points sometimes coincide or occur close together.

An EOQ model is acceptable when the standard deviation of the annual demand is smaller than the actual EOQ value [4].

This study approached the investigation of a multiproduct production and inventory model using the net present value [5]. During the study, comparisons to the EOQ model were regularly made. It was found that as long as deterministic demand is used, the two models vary very little, but with probabilistic or stochastic demand, the differences are major. The EOQ model uses long-run average cost and is fairly simple compared to the complexity of using net present value the results are straight forward and robust.

Two researchers used the base-stock policy in addressing the problem of determining the optimal production and inventory policy for a multi-product production inventory system [6]. The problem concerns homogenous products with an average determined demand for each time period and random demand during the period over an infinite horizon. In order to see effect of optimal production and inventory policy when the products are not homogenous, a heuristic algorithm had to be generated. This developed into a very complex algorithm that had to be implemented on each product.

In a study, it was realized that an EOQ model is not always sufficient when slow and fast moving items are involved in one system [7]. If an EOQ $<1$ is obtained, the items is mismanaged with the wrong inventory model, a Knap-Sack approach will be better for those slow movers, in general, an EOQ model is fully adequate for medium and slow moving items.

\section{Materials and Methods}

J.O. Adimoha's investment is a large wholesale and retail store operated on a self-service basis, selling body spray, assorted perfumes and roll on, body cream, bathing soap, powder, hair cream, hair gel, face cleanser, bathing liquid soap, hair spray and other personal effects.

The supermarket is located at Aba, Abia State Nigeria. The investment was established in 1999. The supermarket 
is characterized by large facilities 150-200 square feet with more than 1,200 items, low profit margins (earning about one percent operating profit on sales), high volume and operations that serve the customer's total need for items.

J.O. Adimoha's investment practices two aspect of inventory control system: physical counting and monitoring inventory and recording and retrieving inventory locations.

The research methodology that was carried out in J.O Adimoha's is adopted by the following methods such as

- Interview

- Problem identification: The problem associated with the supermarket on sales and inventory will first be identified.

- Analysis: Data will be collected for analysis in respect of sales and inventory system of J.O. Adimoha's investment such as report and records.

- Formulation: Before the formulation of the sales and inventory control model of J. O. Adimoha's investment, the sales invoice was considered.

- Implementation: The conceptual inventory model are implanted and tested to ensure that it fulfills the objective.

The investment sells some delicate goods, they decided to have a wooden container to prevent unnecessary shortages during the course of transporting the goods down to the store house and as such, the length, breath and height of the container was taken which measures $126 \mathrm{~cm}$ by $149 \mathrm{~cm}$ by $126 \mathrm{~cm}$. the volumetric factor charge for that container was also taken including the overhead cost per transportation. The estimate of the size of the packing store was taken including the monthly payment for the packing store. The salary of each sales person was also noted.

Due to the vast number of different items being sold in the supermarket, the manager requested that the inventory model will be fairly simple and easy to operate. It was therefore decided that an EOQ model will be developed in an excel database for ease of understanding the model and the program used.

For the furtherance of the project, the combination of a fixed-order EOQ model and multi-product production EOQ model will most probably be sufficient for the improvement of stock control inventory management in this supermarket.

The ABC analysis will also be used because there are fast moving items, medium and slow moving items.

\section{Definition of Terms}

Brief definitions of common inventory control terms were given as [8]:

1. Lead or procurement time: The period of time, expressed in days, week, or month etc. This is the time between the placement of an order and the receipt of order.

2. Demand Level: The amount required by sales, production etc usually expressed as a rate of demand per week, month or year. (This is the most important characteristic in an inventory situation because it shapes the manner in which the inventory problems are analyzed and solved. The demand pattern of an item may be deterministic (when it is assumed that the quantity needed over subsequent periods of time are known with certainty) or probabilistic (when the requirement over a certain period of time are not known but their pattern can be described by a known probability distribution)).

3. Economic order Quantity (EOQ) or Economic Batch Quantity (EBQ): This is a calculated ordering quantity which minimizes the balance of cost between inventory holding costs and reorder cost. It minimizes the total annual inventory cost.

4. Buffer stock or minimum stock or safety stock: A stock allowance to cover errors in forecasting and lead time or the demand during the lead time.

5. Maximum stock Level: This is the amount expressed in units of issue above which the stock should not be allowed to rise. Its purpose is to curb excesses in investment. When this level is reached, it is a signal to defer or cancel outstanding deliveries, if any, it is called upper action level.

6. Reorder level: The level of stock at which a further replenishment order should be placed. The reorder level is dependent upon the lead time and the demand during the lead time.

7. Setup cost or production change cost: Is associated with the changing of materials, equipment and paper work and the removal of previous inventory for the production of a new product.

8. Ordering Cost: This includes all costs related to the placement and retrieval of an order.

9. Purchasing Cost: The variable cost per unit purchased and it includes raw material cost, variable labor and overhead costs, involved with the purchasing of a unit of product.

10. Holding cost or inventory carry cost: The cost linked to a single unit being carried by an organization for a single unit time. It includes all of the following aspect: storage cost, handling cost, insurance cost, taxes or inventory, depreciation and any cost due to breakage, theft, and obsolescence.

11 Shortage cost: This cost is associated to correcting the back order or the cost income due to sales being cost.

\section{Sources And Methods of Data Collection}

Initial meeting and discussions were held with J.O. Adimoha's investment management and possible problem areas in which loss of sales and unexpected fluctuations were identified. The improvement of inventory management concerning stock purchase of some items and loss of sales were selected and data gathering regarding these purchases were collected.

The supermarket supplied a long term data from their database and weekly reports on latest stock control activities (May 2010 to May 2011) were collected on a monthly basis. The data were continually updated as the need arises. Every two weeks, J.O. Adimoha's investment was visited to discuss findings and problems with the data gathered and occasionally information about stock levels was discussed and taken. Unexpected purchase data (from the database) and weekly reports containing daily data of loss of sales were gathered.

\subsection{The Economic Order Quantity Model}


The EOQ model is a relatively basic model that enables organizations to determine the optimal order quantity and order point. These are assumptions and conditions that have to be met to be able to implement the EOQ model [9].

\subsection{Assumptions of a Basic Economic Order Quantity Model}

1. Demand has to be continuous, constant and known (deterministic).

2. Replenishment is constant and known.

3. Lead time has to be zero or at least constant and known.

4. For each order, ordering, setup and holding costs are incurred.

5. All customer demand has to be satisfied, therefore no shortages are allowed.

6. Purchasing prices must be constant and independent from order quantity and time.

7. No inventory in transit is allowed, the delivery cost has to be included in the purchase price.

8. All ordered inventory items has to be independent.

9. Unlimited capital must be available.

10. Planning period has to be infinite.

It must be noted that under specific conditions it is acceptable for demand to be uncertain.

\subsection{Variables of an Economic Order Quantity Model}

$\mathrm{D}=$ Annual demand of unit.

$\mathrm{K}=$ Ordering or setup cost.

$\mathrm{H}=$ Holding cost/unit/year.

$\mathrm{q}_{\mathrm{o}}=$ Optimal order quantity.

$\mathrm{n}_{\mathrm{o}}=$ Optimal order cycle.

$\mathrm{t}_{\mathrm{o}}=$ Optimal order time.

TC $=$ Optimal total cost.

$\mathrm{ROP}_{\mathrm{u}}=$ Re-order point (units).

$\mathrm{ROP}_{\mathrm{t}}=$ Re-order point (time).

$\mathrm{Q}=$ Quantity of units in inventory cycle.

SS $=$ Safety stock.

\subsection{Equation of an Economic Order Quantity} Model

Optimal order Quantity

$$
q_{0}=\sqrt{\frac{2 D K}{H}}
$$

Optimal order time.

$$
t_{0}=\frac{1}{n_{0}}
$$

Total Annual ordering time.

$$
H C=\frac{1}{2} q_{0} H
$$

Reorder point in unit.

$$
\text { ROP }(\text { units })=(S S+L) \text { 'Annual Demand }
$$

Reorder point in time.

ROP $($ time $)=$ Annual Demand 1365 days 'Lead time
Total Annual cost.

$$
\mathrm{TC}=\mathrm{OC}+\mathrm{HC}
$$

Optimal order cycle.

$$
n_{0}=\frac{D K}{q_{0}}
$$

Optimal total cost.

$$
T C_{0}=0.5 q_{0} H+\frac{D K}{q_{0}^{2}}
$$

Total Annual Holding cost.

$$
O C=\frac{D K}{q_{0}}
$$

\subsection{Illustration of an Economic order Quantity Model}

The diagram below is an example of a simple EOQ model. The variables $\mathrm{K}, \mathrm{H}, \mathrm{D}$, and $\mathrm{L}$ have to be entered by the user. The EOQ, order per year, reorder points (units), total holding cost, total ordering cost, and total overall cost will be calculated.

Table 1. Simple Economic Order Quantity Model

\begin{tabular}{|c|c|c|c|}
\hline $\begin{array}{c}\text { Setup/Order Cost } \\
(\mathrm{K})\end{array}$ & $\begin{array}{c}\text { Holding Cost } \\
(\mathrm{H})\end{array}$ & $\begin{array}{c}\text { Annual Demand } \\
(\mathrm{D})\end{array}$ & $\begin{array}{c}\text { Lead Time } \\
(\mathrm{L})\end{array}$ \\
\hline 25.00 & 1.50 & 500 & 6.5 \\
\hline EOQ & 12.9 & $\begin{array}{c}\text { Total Holding } \\
\text { cost }\end{array}$ & 96.82 \\
\hline Order per year & 4 & $\begin{array}{c}\text { Total Ordering } \\
\text { cost }\end{array}$ & 96.82 \\
\hline Reorder Point & 23 & Total cost & 193.65 \\
\hline
\end{tabular}

The diagram below is an idealistic behavior representation of an EOQ model. The demand is constant, there is no lead time and shortages and replenishment occurs at a constant rate.

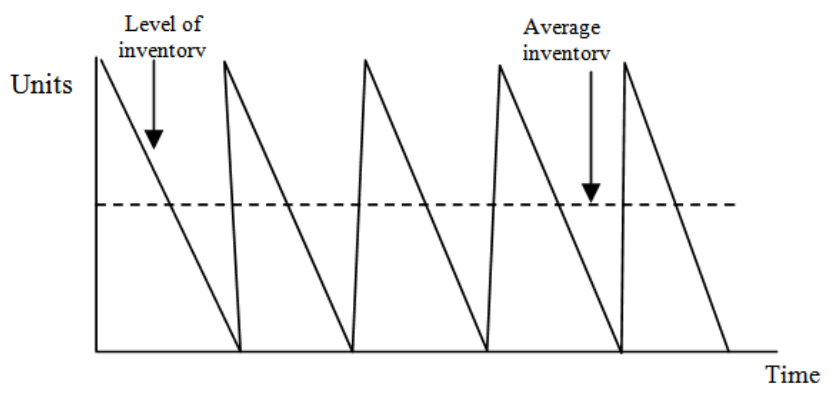

Figure 1. Behavior graph of a Basic Economic order Quantity (EOQ) Model

\subsection{The Economic order Quantity Model with Multiple Products}

The objective of this model will be to establish the optimal order quantity at the optimal time, taking into consideration the inventory levels of all the other items and the lead time to optimize the frequency of spending parcels. 
Table 2. Multi-product Economic Order Quantity (EOQ) Model

\begin{tabular}{|c|c|c|c|c|}
\hline & Item 1 & Item 2 & Item 3 & Item $\mathrm{n}$ \\
\hline Annual demand & 10000 & 1000 & 100 & $\ldots$ \\
\hline Holding cost & 75 & 75 & 63 & $\ldots$ \\
\hline Order cost & 630 & 630 & 41 & $\ldots$ \\
\hline $\mathrm{Q}$ & 410 & 130 & 2.44 & $\ldots$ \\
\hline $\mathrm{N}$ & 24.4 & 4.72 & 149.61 & $\ldots$ \\
\hline t(days) & 14.96 & 47.31 & 130 & $\ldots$ \\
\hline Order quantity & 410 & 3 & 10 & $\ldots$ \\
\hline Total cost & 1 & NI,574.54 & $\ldots$ \\
\hline
\end{tabular}

\subsection{The Economic Order Quantity Model} with Uncertain Demand

According to Winston (2004), an EOQ model may be sufficient as an inventory model when demand of uncertain quantity is adequately approximate to the EOQ. There are two conditions that have to be satisfied. Firstly, good and proper historical data has to be available to establish the average demand that will be required for the model period. Secondly, the EOQ value has to be larger than the standard deviation of the historical demand; otherwise this may lead to under stocking and incur shortage costs.

\subsection{The Effect of Non-zero Lead Time}

The determination of whether or not there will be lead time involved in the replenishment of inventory and the size of this is absolutely crucial to consider when determining the optimal inventory model, else shortages, may occur. The ordering / setup cost and holding cost will be unaffected by lead time and EOQ model that will still optimize and minimize the total cost. The reorder point or level has to be calculated accurately to ensure smooth running of the EOQ model. Whenever this level is reached, an order has to be placed. The lead time can be shorter or longer than the cycle time. Therefore, the reorder point can either be on the current cycle time or in a previous cycle time. The diagram below shows a lead time that is shorter than the cycle time and indicates the reorder point and levels.

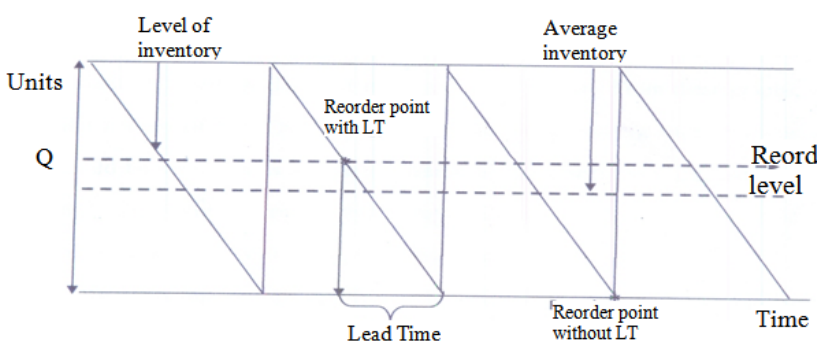

Figure 2. The Effect of lead Time on an Economic Order Quantity Model. Basic EOQ Model

\section{Data Analysis}

In this section, we shall analyze the data gathered for this research. There is currently no automated system in place; data from the weekly report were captured manually using an Excel spreadsheet for easy sorting into identification of items and interpretation.
A graph was constructed for each item used to see and determine when inventory levels are depleted and top-up will be done. From these graphs, the pattern of an EOQ graph for a model with varying time intervals could be seen. It was also again established that there are fast, medium and slow items flows. By merely studying the graphs, possible improvements regarding inventory levels were identified.

The conclusion drawn from the data and graphs was that a multi-product EOQ model with time intervals that vary has to be developed. All the requirements to develop an EOQ model were met, the data collected from J.O. Adimoha's investment provided the years of historical data of the demand for each item.

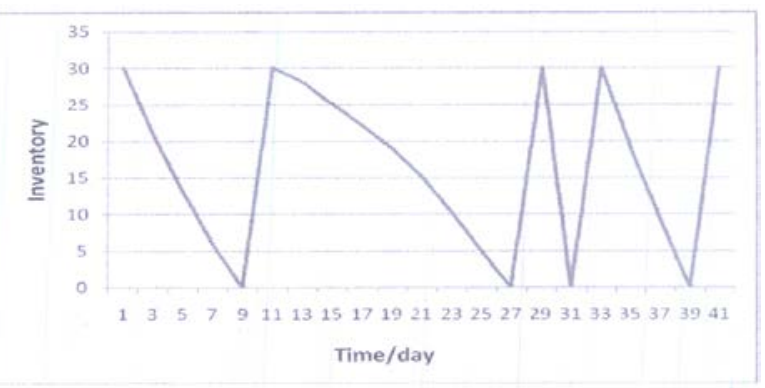

Figure 3. Idealistic Economic Order Quantity Model Graph (With no shortages and varying time interval)

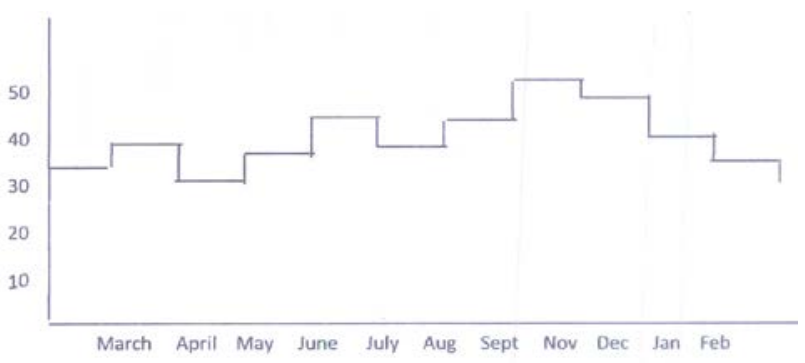

Figure 4. Economic Order Quantity Graph: Body spray

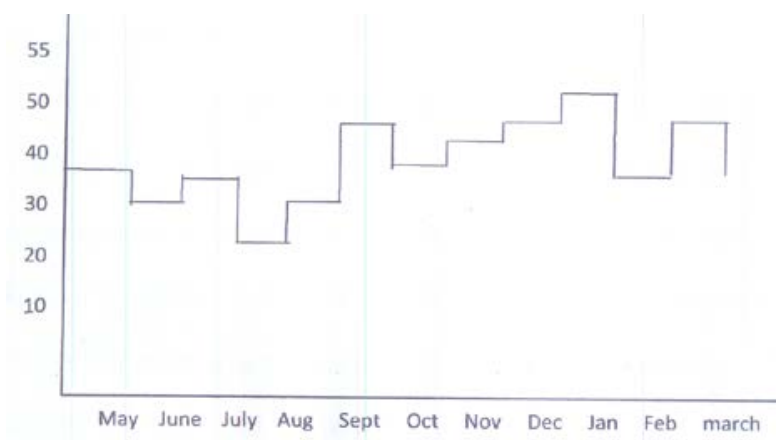

Figure 5. Economic Order Quantity Graph: Perfume 


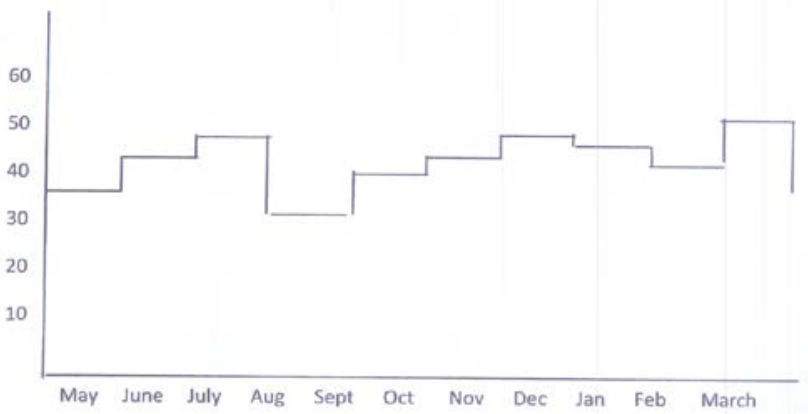

Figure 6. Economic Order Quantity Graph: Powder

Due to the vast number of different items sold in the supermarket, it was observed or noted that the inventory model for J.O. Adimoha's investment will be fairly simple and easy to operate using an EOQ model.

Therefore, in this study, the EOQ model will be developed in an Excel database for easy understanding.

\subsection{ABC Analysis}

An ABC Analysis was conducted for all the items involved in any item purchased. The ABC analysis was conducted in terms of frequency usage. The analysis was conducted by comparing quantities used and the frequency of each kind. The result of the ABC analysis was tabulated as in theory. It can be seen that just over $15 \%$ of the item contributed to nearly $60 \%$ of usage and frequency.

Table 3. ABC Analysis

\begin{tabular}{|c|c|c|c|}
\hline $\begin{array}{c}\text { ABC } \\
\text { Category }\end{array}$ & $\begin{array}{c}\text { Number of } \\
\text { unit }\end{array}$ & $\begin{array}{c}\text { \% of } \\
\text { item }\end{array}$ & $\begin{array}{c}\text { \% of overall usage and } \\
\text { frequency }\end{array}$ \\
\hline A & 17 & $15.50 \%$ & $57.40 \%$ \\
\hline B & 38 & $34.50 \%$ & $33.60 \%$ \\
\hline C & 55 & $50.00 \%$ & $9.00 \%$ \\
\hline Total & 110 & $100 \%$ & $100 \%$ \\
\hline
\end{tabular}

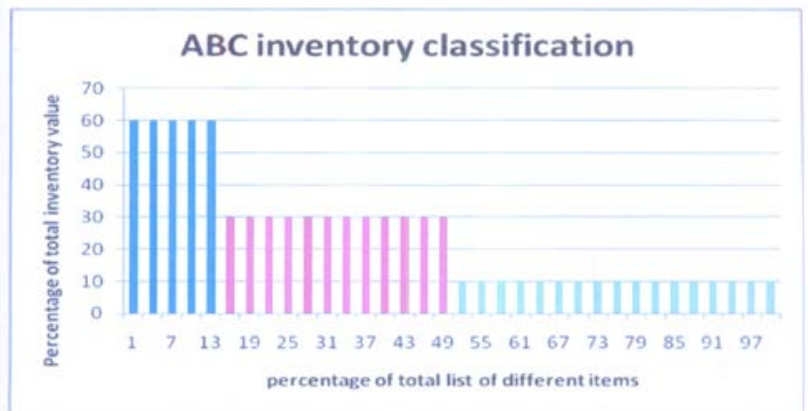

Figure 7. Pareto Graph of ABC Analysis for stock control of item

For the purpose of this paper, it was decided that the focus will only be on the top $5 \%$ of all item, because eventually the same model equations will be incorporated for all the items involved in purchase. This $5 \%$ consist of 5 items; they are tabulated below with their individual contribution to the overall usage

\begin{tabular}{|c|c|c|} 
Table 4. Most frequently used items \\
\hline Items & Unit price(靑) & Overall usage \\
\hline Body spray & 500.00 & $17.72 \%$ \\
\hline Perfume & 1200.00 & $19.69 \%$ \\
\hline Body cream & 1000.00 & $24.40 \%$ \\
\hline Bathing soap & 450.00 & $22.83 \%$ \\
\hline Powder & 400.00 & $15.34 \%$ \\
\hline
\end{tabular}

\subsection{Demand and Standard Deviation}

The annual demand for each item was determined by calculating the average demand of an item per day because all data was in terms of days. This average daily demand is then converted into annual demand by multiplying it by 365 days.

The daily standard deviation was determined. The standard deviation is converted to annual standard deviation by multiplying it with the square root of 365 days.

Annual standard Deviation $=$ Daily Standard Deviation $\sqrt{365}$ days.

Table 5. Daily Standard Deviation of Items

\begin{tabular}{|c|c|c|c|c|c|}
\hline $\mathrm{S} / \mathrm{N}$ & Item $(\mathrm{x})$ & $\begin{array}{c}\text { Mean } \\
(\bar{x})\end{array}$ & $\begin{array}{c}\text { Variance } \\
\left(\mathrm{s}^{2}\right)\end{array}$ & $\begin{array}{c}\text { Std Dev } \\
(\mathrm{s})\end{array}$ & $\begin{array}{c}\text { Annual } \\
\text { Std. Dev }\end{array}$ \\
\hline 1 & Body spray & 40.33 & 19.88 & 4.46 & 19.8858 \\
\hline 2 & Perfume & 43.00 & 29.82 & 5.46 & 29.8158 \\
\hline 3 & $\begin{array}{c}\text { Body } \\
\text { cream }\end{array}$ & 54.08 & 50.27 & 7.06 & 50.2690 \\
\hline 4 & $\begin{array}{c}\text { Bathing } \\
\text { soap }\end{array}$ & 33.92 & 42.08 & 6.49 & 42.1000 \\
\hline 5 & Powder & 32.42 & 51.17 & 7.15 & 51.1462 \\
\hline
\end{tabular}

The mean $(\bar{x})$ is calculated as

$$
\bar{x}=\frac{\sum_{i=1}^{n} x_{i}}{n}(10)
$$

while the variance is obtained as

$$
s^{2}=\frac{\sum_{i=1}^{n}\left(x_{i}-\bar{x}\right)^{2}}{n-1}
$$

The annual variance is given by

$$
s_{A}^{2}=\frac{\sum_{i=1}^{5}\left(x_{i}-\bar{x}\right)^{2}}{5-1} \times 365=\frac{5.2}{4} \times 365=474.5
$$

where $s_{A}^{2}$ the annual variance.

The annual standard deviation is obtained using

$$
\begin{aligned}
s_{A}=\sqrt{\frac{\sum_{i=1}^{5}\left(x_{i}-\bar{x}\right)^{2}}{5-1} \times 365} \\
=\sqrt{\frac{5.2}{4} \times 365}=21.78
\end{aligned}
$$

where $\mathrm{s}_{\mathrm{A}}$ is the annual standard deviation

\subsection{Derivation of Some Basic EOQ Formulae}

$\mathrm{D}=$ Annual Demand.

$\mathrm{Q}=$ Order quantity.

$\mathrm{C}_{\mathrm{o}}=$ Cost of ordering for one order.

$\mathrm{C}_{\mathrm{c}}=$ Carrying cost for one item p.a 


$$
\left.\begin{array}{l}
\text { Average Stock }=\frac{Q}{2} \\
\text { Total Annual Stock Holding cost }=\frac{Q C_{C}}{2} \\
\text { Number of orders per annum }=\frac{Q}{C} \\
\text { Annual ordering Cost }=\frac{D C_{O}}{Q} \\
\text { Total Cost }=\frac{Q C_{C}}{2}=\frac{D C_{o}}{Q}
\end{array}\right\}
$$

The order quantity which makes the total cost (TC) at a minimum is obtained by differentiating with respect to $\mathrm{Q}$ and equating the derivative to zero, to find $\mathrm{Q}$

$$
\begin{aligned}
& \frac{D C_{o}}{Q}=\frac{C_{C}}{2}, 2 \mathrm{DC}_{\mathrm{o}}=\mathrm{Q}^{2} \mathrm{C}_{\mathrm{c}}, \\
& \frac{2 D C_{o}}{C_{c}}=Q^{2}, Q=\sqrt{\frac{2 \times C_{o} \times D Q}{C_{c}}}
\end{aligned}
$$

\subsection{Derivation of EOQ with gradual replenishment}

It will be recalled that gradual replenishment results in a stock level profile of the following shape where replenishment takes over time, $\mathrm{t}$, at rate $\mathrm{R}$.

\subsubsection{Graph or gradual replenishment}

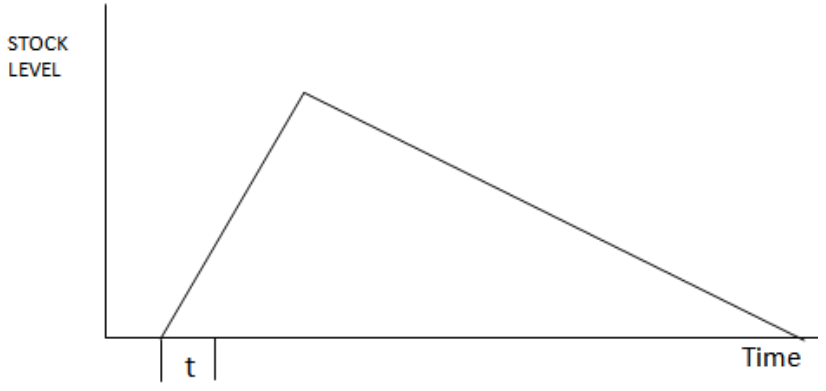

as

$$
\begin{gathered}
\frac{D}{Q} \times R \times t=D \\
t=\frac{Q}{R}
\end{gathered}
$$

The average stock is half the height of the triangle and the height is determined by the rate of replenishment less than demand over the replenishment time.

$$
\text { Average stock }=\frac{t(R-D)}{2}
$$

Substituting for $\mathrm{t}$

$$
\text { Average stock }=\frac{\frac{Q}{R}(R-D)}{2} \text { or } Q \frac{\left(1-\frac{D}{R}\right)}{2}
$$

Total Annual Stockholding cost $=Q \frac{\left(1-\frac{Q}{D}\right) C_{C}}{2}$
The expression can be substituted for the corresponding expression in the already given equation, and the identical steps following, resulting in a modified EOQ formula thus:

EOQ (with gradual replacement) $=\sqrt{\frac{2 \times C_{o} \times D}{C_{C}\left(1-\frac{D}{R}\right)}}(19)$

Table 6. Average Annual Demand and standard Deviation of the
studied items studied items

\begin{tabular}{|c|c|c|}
\hline Items & Average annual demand & Standard deviation \\
\hline Body Spray & 1095 & 19.8858 \\
\hline Perfume & 1460 & 29.8158 \\
\hline Body Cream & 3700 & 50.2690 \\
\hline Bathing Soap & 2920 & 42.1000 \\
\hline Powder & 1095 & 51.1462 \\
\hline
\end{tabular}

\subsection{Ordering Cost}

The ordering cost includes variables of labor and over head costs involved with the purchasing of a unit of products. J.O. Adimoha always uses the same size of container which measures $126 \mathrm{~cm} \times 119 \mathrm{~cm} \times 126 \mathrm{~cm}$. Air freight is charged per kilogram, but this is not necessarily the weight of the parcel. The chargeable weight is either the actual weight of the parcel or the volumetric weight depending which is higher.

$$
\frac{\text { Length }(\mathrm{cm}) \times \text { Breath }(\mathrm{cm}) \times \operatorname{Height}(\mathrm{cm})}{\text { Volumetric factor }}
$$

The volumetric factor used for local air freight is $\$ 6,000.00$ and the current rate at which J.O. Adimoha's investment is charged at is $\$ 100.00$.

The overhead cost per air freight is $\$ 2,500.00$. The supermarket determined that one container can carry SO items of each product.

$$
\begin{aligned}
& \text { The ordering cost per truck }= \\
& \frac{\text { Volumetric weight } \times \mathrm{Z}+\text { overhead cost }}{\text { Total number of item types }}
\end{aligned}
$$

Where $\mathrm{Z}=$ amount per $\mathrm{Kg}$ i.e. $0.1 \mathrm{~kg}$

With the volumetric weight of 314.874 , the ordering cost per truck was calculated as \$50.63.

\subsection{Holding Cost}

Holding cost is made up of storage cost, labor cost, and any other cost incurred for the goods to get to the packing store. The average number of units stored at one time at the packing store has been fixed by J.O. Adimoha's investment to be 1,203 .

$$
\begin{gathered}
\text { Storage cost }=\frac{\text { Storage area } \times \text { monthly rate } \times 12 \text { months }}{\text { average number of units of items }} \\
\text { Labour cost }=\frac{\text { Annual salary }}{\text { Average no of units of items }}
\end{gathered}
$$

With Equations (3.13) and (3.14), storage cost and labor cost were calculated to be $\$ 1,520.20$ and $\$ 59.85$ respectively. The holding cost was then found to be \#l,580.05.

\subsection{Lead Time and Standard Deviation}


From the historical data that were obtained from J.O. Adimoha's investment on average lead time was 12days while the standard deviation was calculated to be 6 days.

\subsection{Safety Stock}

After much discussion, it was decided to keep a safety stock level equivalent to that of 7 days unit usage. This will ensure that even with unexpected fluctuations there will be a sufficient stock of different items.
Table 7. Safety Stock level of items

\begin{tabular}{|c|c|}
\hline Name of item & Safety Stock \\
\hline Body Spray & 7 \\
\hline Perfume & 7 \\
\hline Body Cream & 5 \\
\hline Bathing Soap & 6 \\
\hline Powder & 3 \\
\hline
\end{tabular}

\subsection{The Economic Order Quantity Model}

The EOQ and Order time intervals for the various items were Calculated and Presented in Table 8.

Table 8. The Economic Order Quantity Model of J.O. Adimoba's investment

\begin{tabular}{|c|c|c|c|c|c|}
\hline & Body spray & Perfume & Body cream & Bathing soap & Powder \\
\hline Annual Demand & 1095 & 1460 & 3700 & 2920 & 1095 \\
\hline Unit cost & N400 & N1100 & N900 & N400 & N350 \\
\hline Holding cost & N1580.05 & N1580.05 & N1580.05 & N1580.05 & N1580.05 \\
\hline Ordering cost & N50.629 & N50.629 & N50.629 & N50.629 & N50.629 \\
\hline EOQ & 8.38 & 9.67 & 15.40 & 13.68 & 8.38 \\
\hline Orders per year & 130.668 & 150.982 & 240.259 & 213.450 & 130.668 \\
\hline Orders Time intervals & 2.79 & 2.42 & 1.52 & 1.71 & 2.79 \\
\hline Reorder Points (time) & 36 & 48 & 121.64 & 96 & 36 \\
\hline
\end{tabular}

From the table above, the holding cost and the ordering cost did not change from their values calculated earlier; the other values of the other variables were calculated using these values.

\subsection{Results from the Economic Order Quantity Model}

Table 9. Analysis of Results from the Economic Order Quantity Model

\begin{tabular}{|c|c|c|c|c|c|}
\hline Items & Average Annual Demand & EOQ & Reorder Point & Orders Per year & Order Time Intervals (days) \\
\hline Body spray & 1095 & 8.38 & 36 & 130.668 & 2.79 \\
\hline Perfume & 1460 & 9.67 & 48 & 150.982 & 2.42 \\
\hline Body Cream & 3700 & 15.4 & 121.64 & 240.259 & 1.52 \\
\hline Bathing soap & 2920 & 13.68 & 96 & 213.45 & 1.71 \\
\hline Powder & 1095 & 8.38 & 36 & 130.668 & 2.79 \\
\hline
\end{tabular}

The following table and five graphs illustrate the variation that occurs within the standard deviation range of each item. The reorder point calculated here is the original reorder point plus the safety stock.

It can be deduced from the above table that sometimes the reorder point and order time intervals may occur close together.

Table 10. Range of variables over the standard deviation of items

\begin{tabular}{|c|c|c|c|c|c|}
\hline Items & Average Demand & Stock Level & EOQ & Rafety Stock \\
\hline Body spray & $1077-1113$ & $9-10$ & $7.38-8.38$ & $6-7$ \\
\hline Perfume & $1448-1472$ & $10-12$ & $8.67-10.67$ & $42-44$ \\
\hline Body cream & $3690-3710$ & $15-18$ & $13.40-17.40$ & $54-56$ \\
\hline Bathing soap & $2712-2728$ & $13-16$ & $11.68-15.68$ & $124.64-128.64$ \\
\hline Powder & $1090-1100$ & $6-10$ & $7.38-11.38$ & $101-103$ & $3-5$ \\
\hline
\end{tabular}

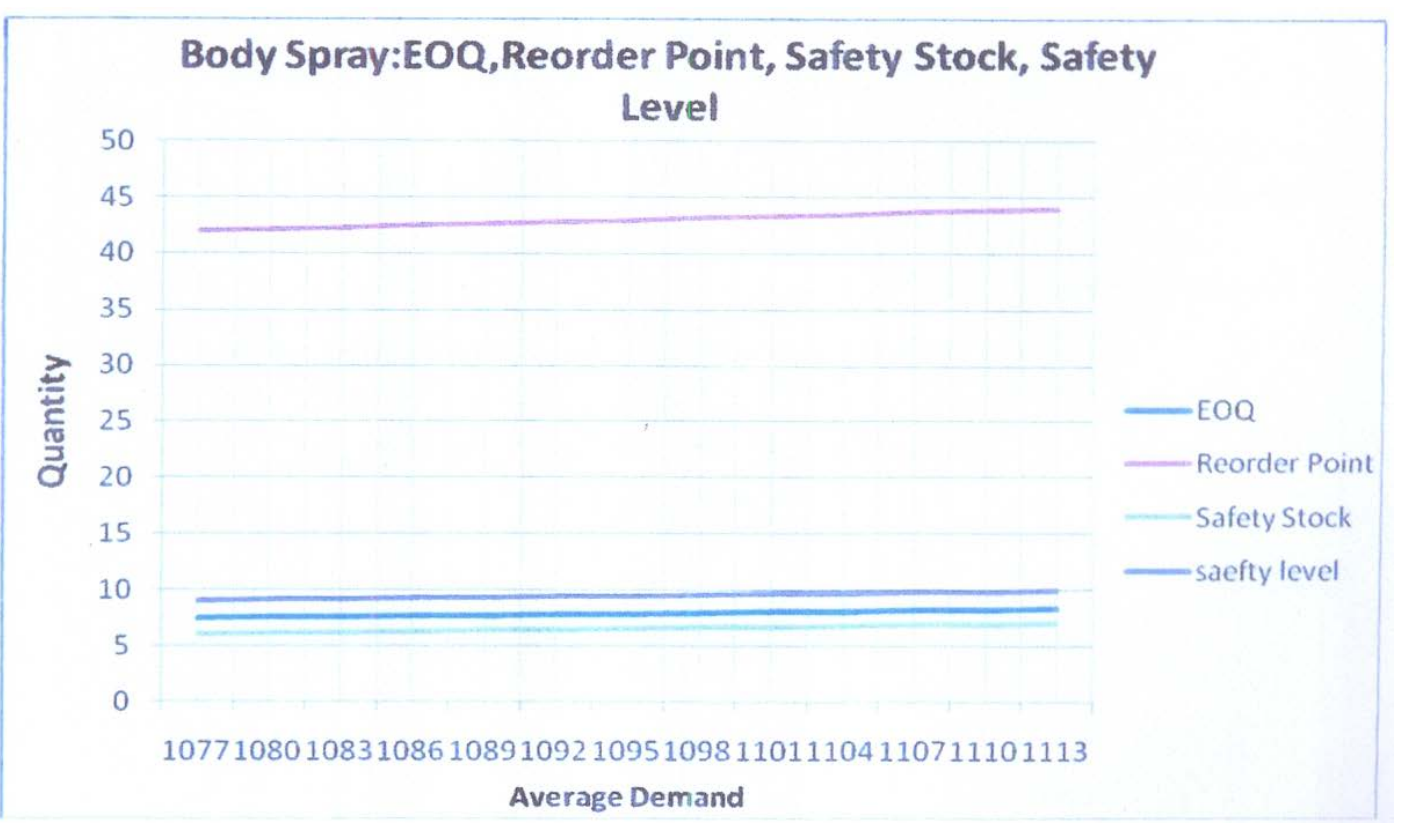

Figure 8. Range of variable over the Standard Deviation of Body spray Demand 


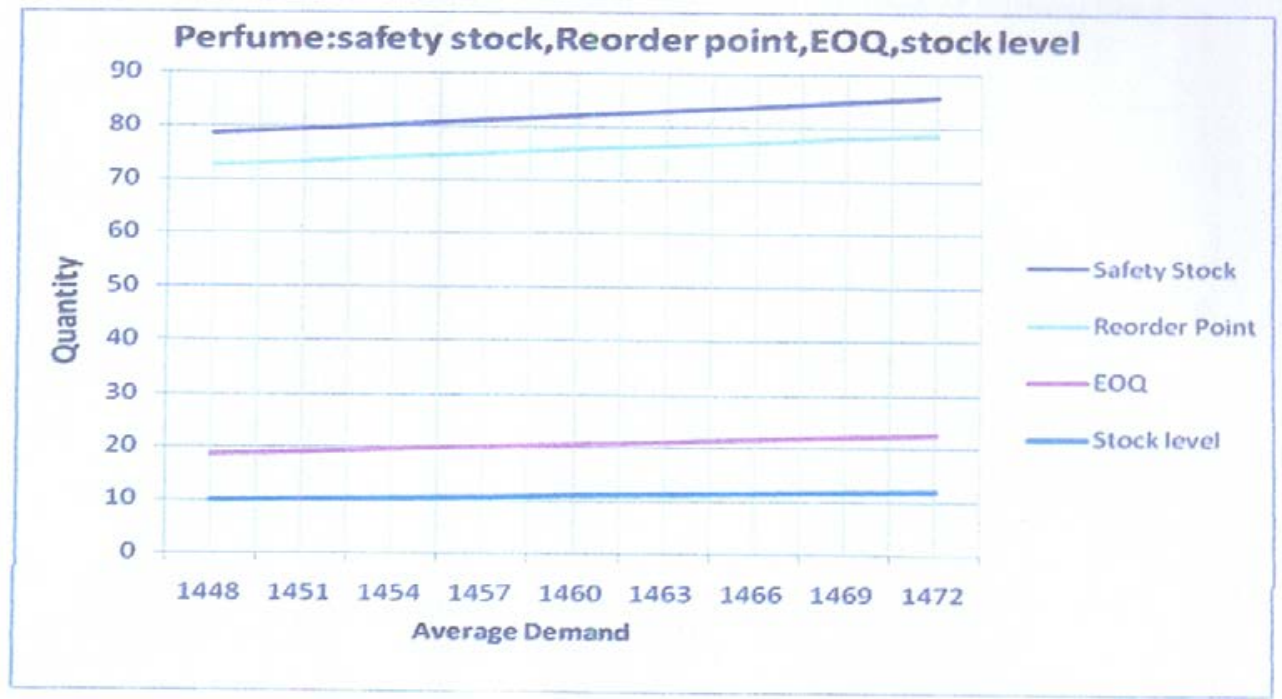

Figure 9. Range of variables over the Standard Deviation of Perfume Demand

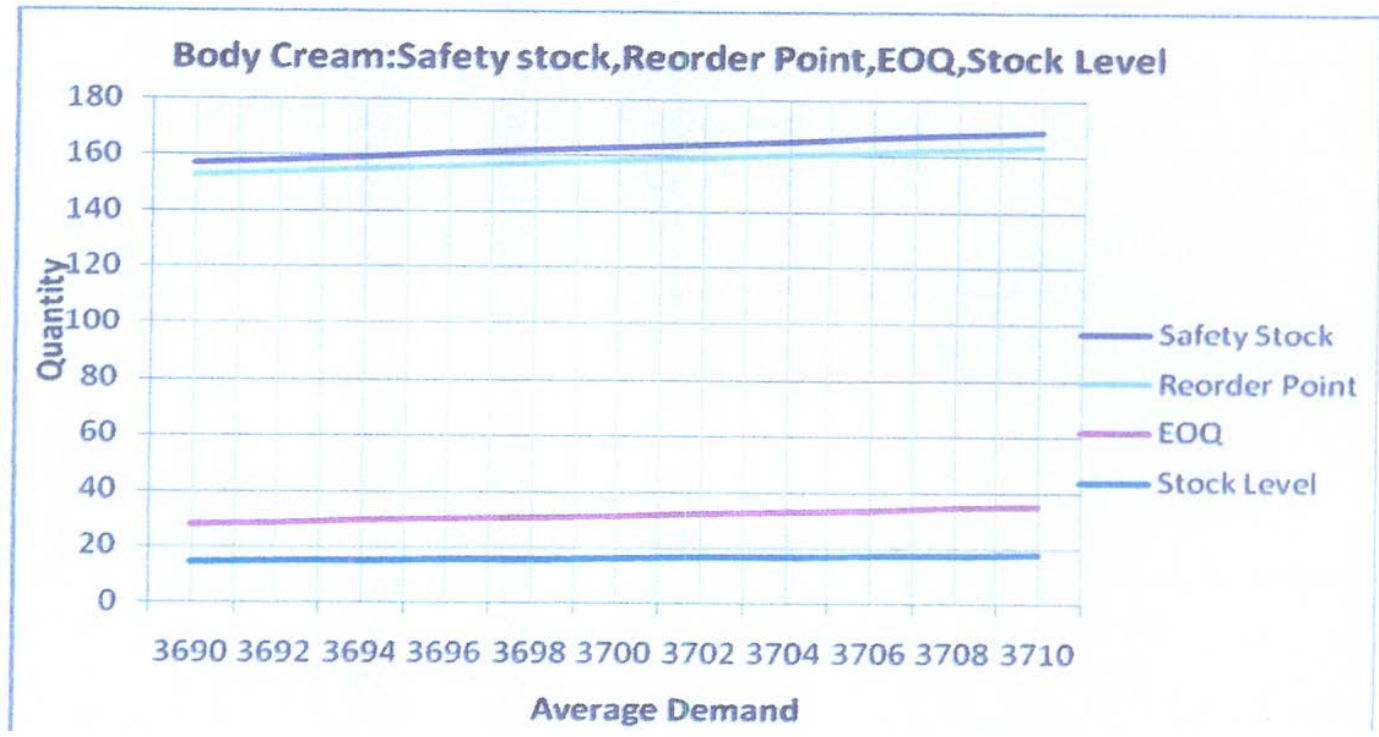

Figure 10. Range of Variable over the Standard Deviation of Body Cream Demand

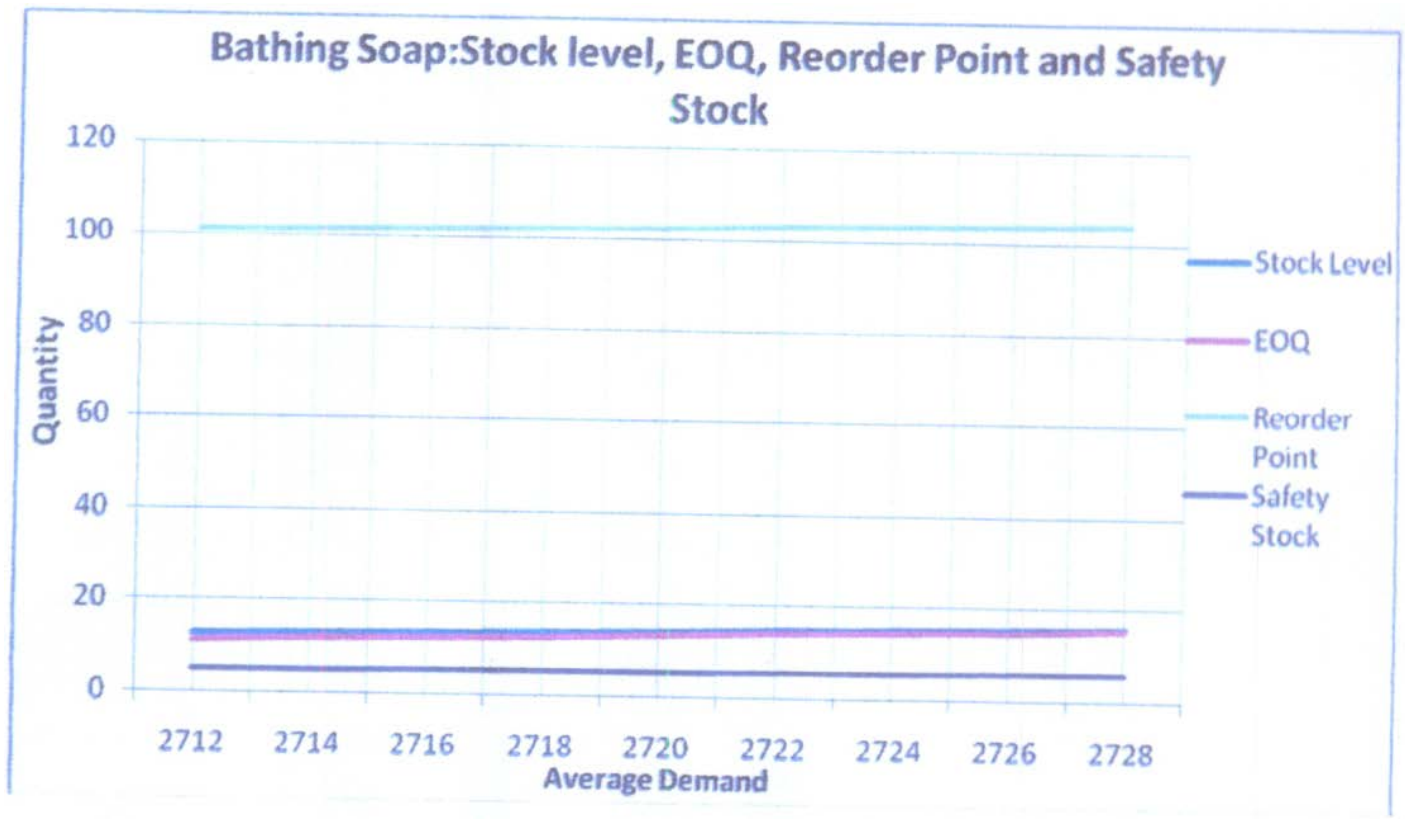

Figure 11. Range of Variables over the Standard Deviation of Bathing Soap Demand 


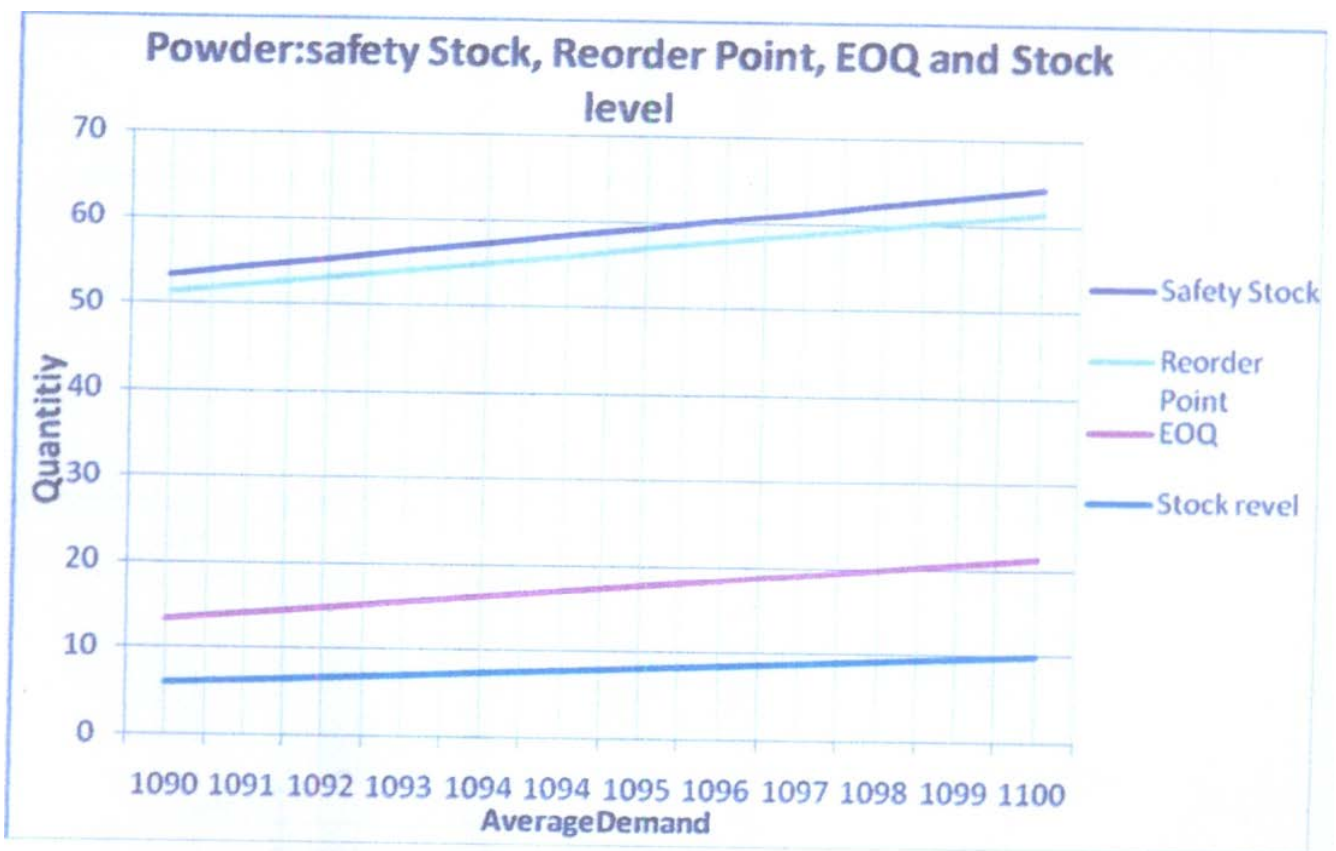

Figure 12. Range of variables over the Standard Deviation of Powder Demand

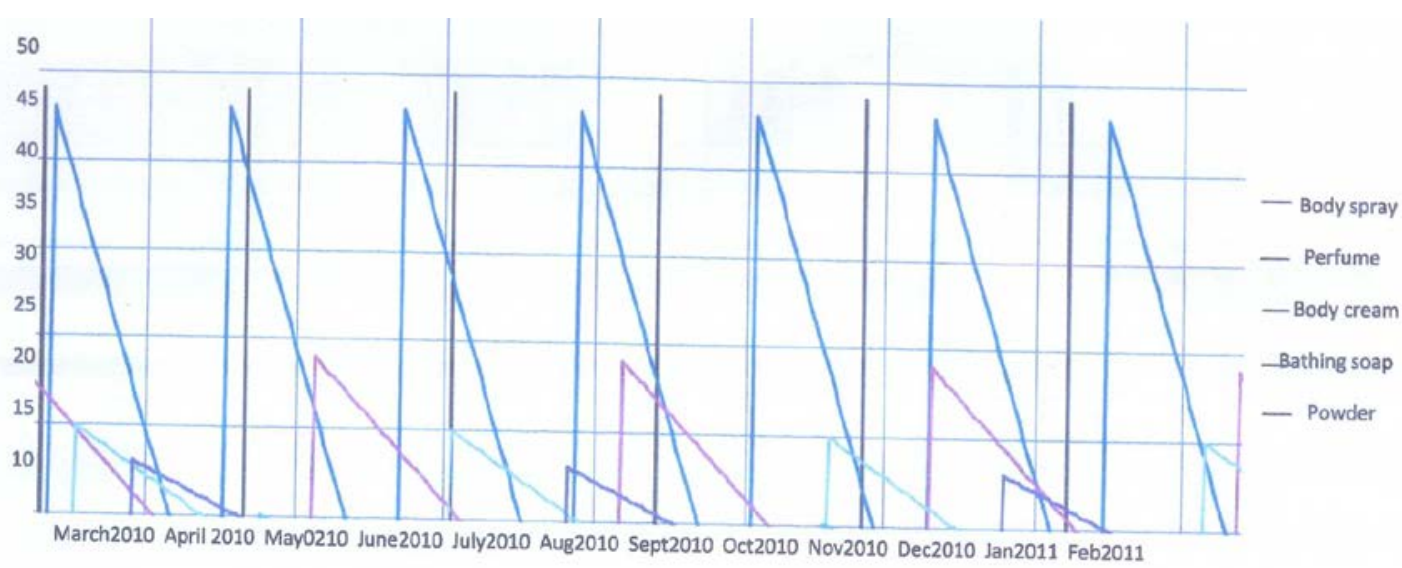

Figure 13. Economic Order Quantity Graph of the 5 most frequently sold of the studied items

\section{Summary}

It was established that J.O. Adimoha's investment does not have a proper inventory management which leads them to sometimes either over stock or under stock.

The decision was made to develop a Multi-product Economic Order Quantity model to determine the optimal order quantities, numbers of cycles and order times which were calculated to be as follows.

\begin{tabular}{|c|c|c|c|}
\hline Items & $\begin{array}{c}\text { Optimal order } \\
\text { quantity } \\
q_{o}=\sqrt{\frac{2 D K}{H}}\end{array}$ & $\begin{array}{c}\text { Number of } \\
\text { cycles } \\
n_{o}=\frac{D}{q_{o}}\end{array}$ & $\begin{array}{c}\text { Order Time } \\
\text { Intervals } \\
t_{o}=\frac{1}{n_{o}} \times 365\end{array}$ \\
\hline Body Spray & 8 & 131 & 3 \\
\hline Perfume & 10 & 151 & 2 \\
\hline Body Cream & 15 & 240 & 2 \\
\hline Bathing soap & 14 & 213 & 2 \\
\hline Powder & 8 & 131 & 3 \\
\hline
\end{tabular}

Also in the cause of this project the frequencies at which different items like perfume, Body cream and Bathing soap can be ordered together were determined. Powder and Body spray can be ordered together as shown in the table above thus minimizing gap of replenishing the stock in order to maintain stock level.

\section{Conclusion}

Since transportation is rather expensive, the combination of orders at different time interval was carefully calculated and constantly updated. From the EOQ graphs that were developed throughout the paper as in Figure 3.11, it can be seen that reorder point sometimes coincide or occur close together. A fairly simple schedule will be tested by J. O. Adimoha's investment to know if modifications are required. The reorder points and EOQs changed and were readjusted and modeled to maintain equilibrium or costs minimization.

Inventory or stock control is a quantitative control technique with strong financial implication. A multiproduct Economic Order Quantity model was used to determine the optimal order times. The combination of orders at different time interval was carefully and constantly updated and verified because reorder points and EOQ may change. In conclusion, it was discovered that reorder points often coincides or happens close together. 


\section{References}

[1] Downs, B.; Metters, R. and Semple, J. (2001). Management Inventory with Multiple Products, lags in Delivery, Resource Constraints and Lost Sales: A Mathematical Programming Approach. Management Science. Volume 47, Number 3. 464-479.

[2] Coyle, J.J.; Bardi, E.J. and Langley, J.C. (2003). The management of Business Logistics: A Supply Chain Perspective. Canada. Thomsom South-Western.

[3] Sune', S.N. (2010). The Development and Optimization of an Inventory Model for Unscheduled Maintenance on Aircraft: A Case Study.

[4] Winston, W.L. (2004). Operations Research: Volume II. Introduction to Probability Models. Canada: Thomson Books/Cole
[5] Queyranne, M. (2002). Production and Inventory Model Using Net Present Value. Operations Research, volume 50, Number 3. 528-537.

[6] Decroix, G.A. and Arreola - Risa, A. (1998). Optimal Production and Inventory Policy for Multiple Products under Resource Constraint. Management Science, Volume 44, Number 7.950-961

[7] Gelders, L.F., and Van Looy, P.M. (1978). An Inventory Policy for Slow and Fast Movers in a Petrochemical Plant: A Case Study. The Journal for the Operational Research Society, Volume 29, Number 9. 867-874.

[8] Mohan, S. and Gopalakrisnan, M. (2007). Analytical Framework for the Multi-item, Economic Order Quantity Model. Production Planning and Control, Volume 18, Number 4. 361-363.

[9] Inyama, S.C. (2007). Operation Research: An Introduction, Supreme Publishers, Owerri. Nigeria. 